Outpatient Community-Acquired Pneumonia: Out of Sight, Away from Prevention

Pneumonia Adquirida na Comunidade em

Ambulatório: Longe da Vista, Longe da Prevenção

Keywords: Ambulatory Care; Community-Acquired Infections; Pneumonia

Palavras-chave: Cuidados em Ambulatório; Infecções Adquiridas na Comunidade; Pneumonia

Dear editor,

Community-acquired pneumonia (CAP) is a common and potentially serious illness with a significant morbidity and mortality rate. The estimated annual incidence of CAP is five to 11 cases per 1000 adults and incidence increases with age and seems to be higher in men than in women. ${ }^{1}$ CAP remains one of the most common medical causes of hospital admission in healthcare systems ${ }^{2}$ and in Portugal, between 2000 - 2009, it was responsible for $3.7 \%$ of the hospitalizations.

After diagnosis, the initial management decision is to determine the location of care: outpatient, hospitalization, or admission to an Intensive Care Unit (ICU). It is essential to avoid unnecessary admissions to avoid the costs and higher consumption of resources and minimize the risk of nosocomial infections by resistant hospital bacteria or thromboembolic events. ${ }^{3}$

The aim of this study was to determine the incidence of CAP in a Portuguese adult outpatient population (over 18 years old) and to characterize those patients, their risk factors and respective vaccination status (seasonal flu and pneumococcal vaccination).

This was a prospective, multi-center and observational study carried out in the ambulatory setting. It involved pulmonologists from Centro Hospitalar Universitário Lisboa Norte with the collaboration of USF-AN (Associação Nacional das Unidades de Saúde Familiar) and family physicians from three Health Units in Northern Portugal. The study was approved by the respective Regional Health Administrations and Ethics Committees. A total of 27711 adults were observed by their family doctor, over a period of one year (between the $1^{\text {st }}$ July 2014 to the 30tth June 2015). We prospectively analyzed all the diagnoses of CAP that were coded with the ICPC- $2^{\circledR}$ code R81 in the problem list and which corresponded to a diagnosis of CAP (viral and bacterial pneumonia, bronchopneumonia and legionnaires' disease, excluding aspiration pneumonia and obstructive pneumonia associated with lung cancer). The inclusion criteria were age over 18 years old and a diagnosis of CAP made according to the standard of care based on clinical and radiological features. The exclusion criteria were patients aged under 18 years old and patients with HIV infection.

In this study, 33 patients with a CAP diagnosis were included, corresponding to an incidence of 1.19 per 1000 adults. The average age was 65.4 years, ranging from 20 to
96 years of age and there were 18 women (54.5\%).

Fifteen $(45.5 \%)$ patients went directly to the hospital emergency room (ER). The family physician was later informed of the diagnosis. In the remaining $19(54.5 \%)$ patients, the diagnosis was made in a primary health care facility. Four of these patients required hospital referral and no patients required hospitalization or died.

In terms of smoking and alcohol habits, 21 (63.6\%) never smoked, $12(36.4 \%)$ had past or active smoking habits, eight $(24.2 \%)$ consumed alcohol regularly and 25 $(75.8 \%)$ did not usually drink alcohol. As for vaccination, nine $(27.3 \%)$ received seasonal flu vaccination (all over 65 years old and entitled to free flu vaccination), while 23 (70\%) did not receive any vaccination. There was only one patient $(3.0 \%)$ that received inoculation with pneumococcal polysaccharide vaccine (PPSV23) and the other 32 (96.7\%) did not receive any inoculation of the PPSV23 vaccine. None of the 33 cases received the pneumococcal 13-valent conjugate vaccine. Sixteen patients $(48.5 \%)$ had, at least, one comorbidity (Table 1).

The main limitation of this study lies in the retrospective diagnosis in almost half of the patients along with the possibility that other cases of CAP may not have been reported. This may compromise some results, namely the low number of cases, low prevalence of smoking and alcohol drinking habits and predominance of female patients. The latter can be explained by the fact that, in general, women consult their family physician more often.

The low vaccination coverage for both the influenza andpneumococcal vaccines should be mentioned. The population that was vaccinated against influenza was included in the groups entitled to free vaccination and without the need for medical consultation, which may explain the difference compared to the pneumococcal vaccine.

According to the expected annual incidence of five to 11 cases per 1000 adults, between 138 and 305 cases of CAP should have been diagnosed in this study, almost four to nine times more than the 33 reported cases. This low number of outpatient diagnoses, compared to the number of hospital admissions, suggests that most patients with

Table 1 - Comorbidities in patients with a diagnosis of CAP (some patients may have multiple comorbidities)

\begin{tabular}{lc}
\hline Comorbidities & $\mathbf{n}(\%)$ \\
\hline Any comorbidity & $16(48.5 \%)$ \\
Obesity (grades 1, 2, 3) & $11(33.3 \%)$ \\
Renal failure & $7(21.2 \%)$ \\
Diabetes mellitus & $6(18.2 \%)$ \\
Cardiac failure & $5(15.2 \%)$ \\
Cancer & $4(12.1 \%)$ \\
Asthma & $3(9.1 \%)$ \\
COPD & $3(9.1 \%)$ \\
Hepatic disease & $1(3.0 \%)$ \\
\hline
\end{tabular}


CAP sought care directly in the ER, instead of seeking their family physician first.

This diversion of patients from Primary Health Care directly to the hospital ER with reduced monitoring of patients with pneumonia by family physicians can make it more difficult to implement preventive measures, namely flu and pneumococcal vaccination.

The impact and severity of CAP justify additional studies in the outpatient setting that would allow a better characterization of this disease and promote a greater awareness for its prevention.

\section{AUTHORS CONTRIBUTION}

All authors contributed equally to the concept, draft, review and edition of the work.

\section{PROTECTION OF HUMANS AND ANIMALS}

The authors declare that the procedures were followed

\section{REFERENCES}

1. Welte T, Torres A, Nathwani D. Clinical and economic burden of community-acquired pneumonia among adults in Europe. Thorax. 2012;67:71-9.

2. Wunderink RG, Waterer G. Advances in the causes and management of community acquired pneumonia in Adults. BMJ. 2017;358:2471. according to the regulations established by the Clinical Research and Ethics Committee and to the Helsinki Declaration of the World Medical Association updated in 2013.

\section{DATA CONFIDENTIALITY}

The authors declare having followed the protocols in use at their working center regarding patients' data publication.

\section{COMPETING INTERESTS}

The authors have declared that no competing interests exist.

\section{FUNDING SOURCES}

This research received no specific grant from any funding agency in the public, commercial, or not-for-profit sectors.

3. Mandell L, Wunderink R, Anzueto A, Bartlett J, Douglas Campbell G, Dean N, et al. Infectious Diseases Society of America/American Thoracic Society Consensus Guidelines on the Management of CommunityAcquired Pneumonia in Adults. IDSA/ATS Guidelines for CAP in Adults; CID 2007:44.

\section{Mónica PEREIRA $\rrbracket^{1}$, António DINIZ ${ }^{1}$, Filipe FROES ${ }^{1}$}

1. Thorax Department. Centro Hospitalar Universitário Lisboa Norte. Lisbon. Portugal.

Autor correspondente: Mónica Pereira. monicahcpereira@gmail.com

Recebido: 19 de abril de 2021 - Aceite: 11 de junho de 2021 - Online issue published: xx de julho de 2021 - Online issue published: 01 de setembro de 2021

Copyright $\odot$ Ordem dos Médicos 2021

https://doi.org/10.20344/amp.16416 